\title{
SELECTION OF PROJECT MANAGEMENT TOOL: AN EX-POST FACTO CASE STUDY
}

\begin{abstract}
Brazilian federal law imposes to state organizations the supplier selection on price. Private organizations also adopt this rule, mainly by costs optimization or simplicity. However, lower-cost inputs do not guarantee lower-cost outputs. That is, lower-cost supplies may imply in higher-cost production, for instance, due to rework. Besides of that, producers may look for higher benefits instead of lower costs. For these reasons, even the federal law allows supplier selection on benefits, in justified cases. This paper presents a real case on supplier selection in a Brazilian company of fuel distribution. Since it was in a private company, a senior project manager could select a project management tool considering only benefits. An ex-post facto analytic hierarchy process application considered detailed benefits and costs. The results are compared in the end.
\end{abstract}

Keywords: analytic hierarchy process, case study, project management, supplier selection.

\section{Introduction}

Supplier selection on price is a simple rule: the cheaper supplier will be the selected one. Brazilian federal law (Federal Republic of Brazil, 1993) imposes the rule to state organizations (including agencies, companies, foundations and universities). The main arguments on this rule are costs optimization and simplicity. Therefore, sometimes, private organizations also perform supplier selections only on price.

Nevertheless, lower-cost supplies may imply in higher-cost production, for instance, due to rework. Besides of that, producers may look for higher benefits than lower costs or even higher benefit/cost ratios. For these reasons, Brazilian federal law allows supplier selection on benefits, in justified cases. In these cases, the law allows supplier selection based on "best technics" or based in mixed price and technics. This way, supplier selection becomes subjective. As a consequence, in the last decades, supplier selection has received extensive attention in supply chain management (SCM) literature (Bruno et al., 2016). Multi-criteria decision analysis (MCDA) methods has been applied to supplier selection by state or private organizations. Analytic hierarchy process (AHP) is a leading MCDA method, also in SCM literature (Tramarico et al., 2015).

This paper presents a real case of supplier selection performed by a Brazilian company of fuel distribution. This is a private company, then, considering only benefits, a senior project manager selected a supplier. He did select the highest price supplier. Afterwards, AHP was applied to investigate and justify his choice. Therefore, this is an ex-post facto AHP application. Decision includes ten criteria and three alternatives. 


\section{Literature Review}

A project is a temporary endeavor designed to produce a unique product or service (Project Management Institute, 2017a). Project management (PM) is the application of knowledge, resources, skills, and tools, to meet the project requirements. Project portfolio is a collection of current or proposed projects. Project portfolio management (PPM) is the centralized management of projects in a portfolio to meet strategic business objectives (Project Management Institute, 2017b).

Origins of PM are connected with mankind history. Egyptian Pyramids and Sphynx construction, biblical passages as Noah's Ark and the Crossing of Red Sea, and Roman Empire conquests. All they are ancient examples of PM. Until 1900, PM discipline is understood as more an art than a science (Lock, 2013). From the beginning of last century, with Scientific Management, PM became scientific. One of the first PM tool was the Gantt chart, a bar chart to time planning and controlling. In the middle of the 20th Century, Program Evaluation and Review Technique and Critical Path Method (PERT/CPM) were developed, enhancing resource allocation and risk analysis. In the end of century, emerged new tools as guides, standards and software to PM (Ahmad \& Laplante, 2006).

\section{Objectives}

Nowadays, PM seems to be impracticable without software tools. Time planning, resource allocation, and project integration are some of PM processes supported by software tools. There are a wide variety of PM software, for instance, from open source to cloudcomputing enabled packages. However, this variety creates a decision problem: which tool to select? Thinking on services, that is the implementation and post-sale services, the decision becomes a supplier selection problem.

The provider of PM software will play an important role in the business of the organization. Supplier selection on price is not indicated due to these strategic implications. MCDA seems to be a proper way for this decision-making. This paper presents a real case of supplier selection of PM software, considering benefits and costs. AHP is the MCDA method applied in the case.

\section{Methodology}

This paper presents a case study on a division of one of the major industrial groups operating in Brazil. The group is mainly focused on fuel production and distribution. But, the group also includes pharmacies and other service providers regarding to chemicals products. This case is on the division of liquefied petroleum gas (LPG) distribution to households in Brazilian Southeast, including States of Rio de Janeiro and Sao Paulo.

A senior project manager becomes a portfolio manager. Then, he needed to standardize PM software used in LPG division. Only a few PM software packages satisfy requirements of LPG division. Some providers can work with more than one software developer. Let us call them, Software Providers 1, 2 and 3 (SP1, SP2, and SP3). SP1 and SP2 are the largest providers in Brazil, and they are subsidiaries of worldwide providers of PM software. SP3 is a local provider of PM software and consultancy. Despite being not the cheapest, project manager selected SP1. That is, supplier selection was not on price. The main justification is higher-benefit expected with SP1. All these benefits were confirmed, after the supplier selection, when SP1 started to provide the PM software. 
However, there are some doubts hovered in the air: Were the project manager feelings correct? Has SP1 the best benefit/cost ratio?

To answer those questions, AHP was applied. Only the senior project manager for LPG division provided judgements (pairwise comparisons) and he also identified criteria, adapting the model proposed by Ahmad \& Laplante (2006) to Brazilian case. Senior manager did not know AHP before. AHP was introduced in LGP by the second author of this paper, after she was hired as a PM trainee by the company. For AHP application, no specific MCDA software was applied. That is, AHP was applied only with electronic spreadsheets, developed by PM trainee.

\section{Data Analysis}

Table 1 presents a comparison matrix (A) among decision criteria to supplier selection of PM software for the LPG division. The priorities of the criteria were obtained with normalization of comparison matrix's right eigenvector $(\mathbf{w})$. The consistency ratio of the comparison matrix is $C R=0.063$. This is a very good $C R$, since there were ten criteria compared.

Table 1

Pairwise comparisons of criteria

\begin{tabular}{llllllllllll}
\hline & A & B & C & D & E & F & G & H & I & J & Priority \\
\hline Portfolio management (A) & 1 & $1 / 7$ & $1 / 5$ & $1 / 3$ & $1 / 3$ & $1 / 7$ & $1 / 7$ & $1 / 9$ & 5 & $1 / 3$ & $2 \%$ \\
Time planning (B) & & 1 & 3 & 5 & 5 & 1 & 1 & $1 / 3$ & 9 & 5 & $16 \%$ \\
Task management (C) & & & 1 & 3 & 3 & $1 / 3$ & $1 / 3$ & $1 / 5$ & 7 & 3 & $8 \%$ \\
Risk management (D) & & & & 1 & 1 & $1 / 5$ & $1 / 5$ & $1 / 7$ & 5 & 1 & $4 \%$ \\
Change management (E) & & & & & 1 & $1 / 5$ & $1 / 5$ & $1 / 7$ & 5 & 1 & $4 \%$ \\
Resource allocation (F) & & & & & & 1 & $1 / 3$ & $1 / 3$ & 5 & 5 & $14 \%$ \\
Costs (G) & & & & & & & 1 & $1 / 3$ & 7 & 5 & $18 \%$ \\
Demand management (H) & & & & & & & & 1 & 9 & 7 & $30 \%$ \\
Financial management (I) & & & & & & & & & 1 & 5 & $2 \%$ \\
Integration (J) & & & & & & & & & & 1 & $3 \%$ \\
\hline
\end{tabular}

As it can be seen in Table 1, demand management is the criterion with highest priority. It is clearly related with LGP division, since its division is almost directly connect to end customers (households). Therefore, the service level must be high, which requires a good demand management.

For each criteria, senior project manager pairwise compared alternatives. For instance, Table 2 presents comparisons regarding to A. The comparison matrix is totally consistent with $C R=0$. Since this a selection problem, priorities of alternatives were obtained with ideal synthesis, which means normalization with $\max \left(w_{j}\right)=1$, and not with $\Sigma\left(w_{j}\right)=1$.

Table 2

Pairwise comparisons of alternatives regarding to portfolio management

\begin{tabular}{lllll}
\hline & SP1 & SP2 & SP3 & Priority \\
\hline SP1 & 1 & 1 & 7 & 1 \\
SP2 & & 1 & 7 & 1 \\
SP3 & & & 1 & 0.143 \\
\hline
\end{tabular}


Similar comparisons were performed by the project manager in the same meeting. All $C R$ were lower than 0.1. Table 3 presents priorities for alternatives, regarding to each criterion (local priorities). Overall priorities of alternatives were obtained adding their local priorities weighted by priorities of criteria (Table 1 ).

Table 3

Local an overall priorities

\begin{tabular}{llllllllllll}
\hline & A & B & C & D & E & F & G & H & I & J & Overall \\
\hline SP1 & 1 & 1 & 1 & 1 & 1 & 1 & 0.281 & 1 & 1 & 1 & 0.873 \\
SP2 & 1 & 1 & 0.333 & 1 & 1 & 1 & 0.079 & 1 & 0.442 & 1 & 0.775 \\
SP3 & 0.143 & 0.333 & 0.333 & 0.333 & 0.333 & 0.200 & 1 & 0,116 & 0,084 & 1 & 0.378 \\
\hline
\end{tabular}

As previously selected by the project manager, SP1 has the highest priority in the AHP expost facto application. Curiously, SP2 was dominated by SP1. That is regarding to all criteria, priority for SP1 was equal or better than SP2. Local priority of SP1 is not the best only regarding to costs (Criterion G). A sensitivity analysis shows that only if priority of costs be increased from $18 \%$ to $46 \%$, overall priorities of SP1 and SP3 will tie at 0.57 . From that value, i.e., with more than $46 \%$ priority for costs, company should select SP3.

\section{Conclusions}

This work presented an ex-post facto application of AHP for the supplier selection of project management tool. That is, a senior project manager had previously selected a supplier for this toll (PM software), considering only subjective benefits. Even with the confirmation of these benefits, there was still uncertain if this was the best choice for the company. With AHP it was possible to measure the performance of different suppliers regarding subjective criteria. It was also possible to incorporate quantitative criterion, measured by decision maker perception: costs.

Some priorities for different alternatives were the same according to various criteria. This is an indication that there is possible to exist dependence among criteria or among alternatives. Then, another MCDA could be properly applied to this decision analysis: the analytic network process (ANP). An ANP application should consider dependences and feedback among alternatives and criteria.

Another limitation for this research is on data collection. The pairwise comparisons were provided only by a senior project manager. This is legitimate, considering that this paper presents a case study. However, it will be interesting to study similar decisions on supply chain management or project management considering comparisons from different managers. Group decision-making techniques may be applied enhancing the scientific aspects of the research.

\section{Acknowledgments}

This research was financially supported by National Council for Scientific and Technological Development (CNPq) and Sao Paulo State Foundation, Grant No. FAPESP 2017/22963-6. 


\section{Key References}

Ahmad, N. \& Laplante P. A. (2006). Software project management tools: making a practical decision using AHP. Proceedings of the Annual IEEE/NASA Software Engineering Workshop, Columbia, MD, April 6-7, 2006, p. 76-84.

Bruno, G., Ciardiello, F., Esposito, E., Genovese, A. \& Piccolo, C. (2016). A critical comparison of multi-criteria methodologies for supplier selection. Proceedings of the International Symposium on the Analytic Hierarchy Process, London, UK, August 4-7, 2016, p. 140.

Federal Republic of Brazil (1993). Lei 8.666 de 21 de junho de 1993, available at: https://www.planalto.gov.br/ccivil 03/leis/18666cons.htm.

Lock, D. (2013). Project management. Tenth edition, Farnham, UK: Gower.

Project Management Institute (2017a). A guide to the project management body of knowledge. Sixth edition, N. Square, PA: PMI.

Project Management Institute (2017b). The standard for portfolio management. Fourth edition, N. Square, PA: PMI.

Tramarico, C. L., Mizuno, D., Salomon, V. A. P. \& Marins, F. A. S. (2015). Analytic hierarchy process and supply chain management: A bibliometric study. Procedia Computer Science, 55, p. 441-450. 